\title{
Translation reinitiation and development are compromised in similar ways by mutations in translation initiation factor elF3h and the ribosomal protein RPL24
}

Fujun Zhou ${ }^{1,3}$, Bijoyita Roy², Albrecht G von Arnim²

\begin{abstract}
Background: Within the scanning model of translation initiation, reinitiation is a non-canonical mechanism that operates on mRNAs harboring upstream open reading frames. The h subunit of eukaryotic initiation factor 3 (elF3) boosts translation reinitiation on the UORF-containing mRNA coding for the Arabidopsis bZip transcription factor, AtbZip11, among others. The RPL24B protein of the large ribosomal subunit, which is encoded by SHORT VALVE1, likewise fosters translation of UORF-containing mRNAs, for example mRNAs for auxin response transcription factors (ARFs).

Results: Here we tested the hypothesis that RPL24B and elF3h affect translation reinitiation in a similar fashion. First, like eif3h mutants, rp/24b mutants under-translate the AtbZip11 mRNA, and the detailed spectrum of translational defects in rpl24b is remarkably similar to that of eif3h. Second, eif3h mutants display defects in auxin mediated organogenesis and gene expression, similar to rp/24b. Like AtbZip11, the UORF-containing ARF mRNAs are indeed undertranslated in eif3h mutant seedlings.

Conclusion: We conclude that, similar to elF3h, RPL24B bolsters the reinitiation competence of uORF-translating ribosomes. Coordination between elF3 and the large ribosomal subunit helps to fine-tune translation of uORFcontaining mRNAs and, in turn, to orchestrate plant development.
\end{abstract}

\section{Background}

In eukaryotic cells, gene expression is highly regulated, often at multiple levels, such as transcription, mRNA structure and stability, translational control, and protein degradation. Translational regulation is arguably least well characterized, and questions concerning the mechanism of translational control abound. In metazoans and fungi, translation is regulated in response to nutritional and metabolic signals and in certain developmental contexts [1-3]. In plants, translation is regulated by small metabolites as well as environmental conditions [4-7].

According to the canonical model of eukaryotic translation, the ribosome dissociates from the mRNA for

\footnotetext{
* Correspondence: vonarnim@utk.edu

${ }^{2}$ Department of Biochemistry, Cellular and Molecular Biology, The University of Tennessee, Knoxville, TN 37996, USA

Full list of author information is available at the end of the article
}

good as soon as it has terminated translation at a stop codon. However, there are exceptions to this rule. In Arabidopsis, about $30 \%$ of full-length mRNAs harbor one or more upstream open reading frames (uORFs) in their $5^{\prime}$ leader sequence [8]. Once a uORF has been recognized and translated, the ribosome must resume scanning and reacquire its initiation factors in order to recognize the start codon of the main ORF, a process known as reinitiation. The efficiency of translational reinitiation is inversely related to uORF length. In yeast, for example, a 35-codon uORF all but abolishes translation downstream [9]. However, a small fraction of Arabidopsis uORFs exceeds this length. While uORFs generally inhibit translation, certain uORFs regulate translation in response to exogenous signals, for example, sucrose or polyamines $[5,10,11]$.

In Arabidopsis, carboxyl-terminal truncation alleles of eIF3h cause under-translation of specific mRNAs, many of 
which harbor multiple upstream open reading frames (uORFs) in their $5^{\prime}$ leader $[8,12]$. The h subunit of eukaryotic translation initiation factor, eIF3, ameliorates the inhibitory effect of specific uORFs in part by promoting the reinitiation competence of the translating ribosome [13].

Among the eukaryotic translation initiation factors, eIF3 is by far the most complex. It consists of 12 subunits in Arabidopsis [14]. The functions of the individual eIF3 subunits remain to be fully characterized. eIF3 participates in almost all major steps during initiation, such as tRNA charging of the $40 \mathrm{~S}$ ribosomal subunit; and loading of the charged $40 \mathrm{~S}$ onto the mRNA's $5^{\prime}$ Untranslated Region (UTR) [15]. eIF3 also affects mRNA scanning and start codon recognition [16-18]. Moreover, eIF3 may help with dissociating post-termination ribosomes into their large and small subunits and thereby facilitate ribosome recycling [19]. The h subunit of eIF3 is not conserved in budding yeast, but forms part of the functional core of mammalian eIF3 [20].

Aside from eIF3h, another plant-encoded protein that fosters translation of uORF-containing mRNAs is the large ribosomal protein, RPL24B. Deletion mutations in RPL24B/SHORT VALVE (STV) cause defects in organ initiation, vascular patterning, and gynoecium structure, which have been attributed in part to undertranslation of mRNAs for transcription factors of the auxin response factor (ARF) class [21]. Auxin plays critical roles in the initiation and specification of postembryonic organs emerging from the apical meristems as well as in the establishment of the apical-basal axis [22-24]. The short-range directional auxin transport governs primordium initiation on the shoot apical meristem (SAM), thereby affecting phyllotaxis $[25,26]$. While PIN proteins guide directional auxin transport, ARFs are transcriptional regulators that convert the local auxin concentration into a gene expression response (reviewed by [27]). Among the latter, ARF5/MONOPTEROS helps to establish the apical-basal axis $[28,29]$, whereas ARF3/ETTIN has multiple roles in defining the dorsoventrality of leaves and in gynoecium development [30-32].

Here we address the question whether RPL24B and eIF3h contribute to reinitiation in distinct ways or similar ways. As a model system, we utilize the $5^{\prime}$ leader of the Arabidopsis bZip11 gene, which harbors 4 uORFs. Of these, the second is strongly inhibitory to translation and is physiologically important because it mediates a translational repression by sucrose $[7,10,11,13]$. We demonstrate that mutations in RPL24B and eIF3h have a similar spectrum of defects in the translation of a panel of mutant versions of the AtbZip11 mRNA. In addition, like $r p l 24 b / s t v 1$, eif3h mutant plants display defects in auxin responses. And, finally, eif $3 h$ mutant plants undertranslate the uORF-containing mRNAs for several ARF auxin response factors, including ARF3 and
ARF5, which are clients of RPL24B. These data raise the strong possibility that the initiation factor eIF3 cooperates with the large ribosomal subunit in bringing about translation reinitiation.

\section{Results}

A mutant of RPL24B displays similar translation defects as does eif $3 h$

The stv1-1 deletion mutation truncates the RPL24B gene, and is henceforth referred to as rpl24b. We examined whether $r p l 24 b$ displays gene expression defects similar to the carboxyl-terminal deletion allele of eIF3h, eif $3 h-1$. Indeed, translational efficiency on the uORFcontaining mRNA of Arabidopsis bZip11 was reduced in $r p l 24 b$, similar to eif3h-1 (Fig. 1A). Notably, the reporter gene was expressed normally when the uORFs were removed. In previous research, we had employed a series of two dozen mutated versions of the AtbZip11 5' leader in order to narrow down the likely molecular defect in eif3h [13]. This series of constructs was used here to compare rpl24b with eif $3 h$. In the first set of constructs, individual uAUGs in the context of the AtbZip11 leader were fused directly to the FLUC coding sequence in order to compare uAUG recognition. $R p l 24 b$ mutants did not display any defect in start codon recognition, whether the AUG was in a weak or strong context (Fig. 1B). Next, we addressed whether reinitiation after $\mathrm{UORF} 2$ and 3 was sensitive to the uORF peptide sequence. The UORF2 peptide sequence is inhibitory to translation in wild type and eif3h [13]. The coding sequence of uORF2 and 3 was changed using compensatory frameshift mutations and additional site-directed mutagenesis [13]. The data show that $r p l 24 b$ mutants were as sensitive as eif $3 h$ mutants to the coding sequences of the UORF2 and uORF3 peptides (Fig. 1C). In the following, we tested the dependence of reinitiation on the length of the spacer between uORFs and main ORF. While wild-type plants were able to reinitiate translation downstream of a simplified uORF cluster as long as the spacer sequence was equal to or longer than 50 nucleotides, $r p l 24 b$ mutants could not reinitiate here, again similar to eif3h mutant plants (Fig. $2 \mathrm{~A})$. One might hypothesize that the $r p l 24 b$ or eif $3 h$ mutations cause a relaxation of start codon recognition specifically for reinitiating ribosomes. If so, the defect in the mutants would be due - not to a failure to resume scanning but - to premature initiation at non-AUG codons in the 213nt spacer sequence, which could easily cause a failure to recognize the AUG start codon of FLUC. In this case, shortening the spacer sequence would have ameliorated the mutant defect, resulting in increased FLUC expression. Evidently, this was not the case. It stands to reason that neither the eif3h mutant nor $r p l 24 b$ have relaxed start codon recognition. 
A
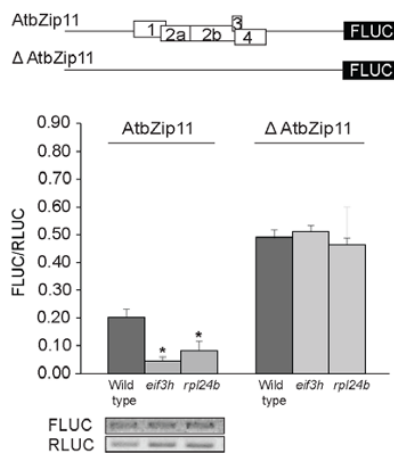

B
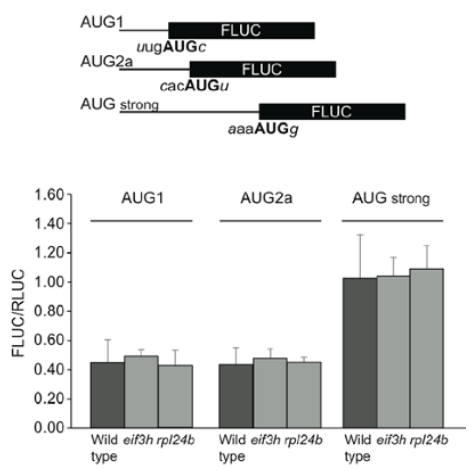

C

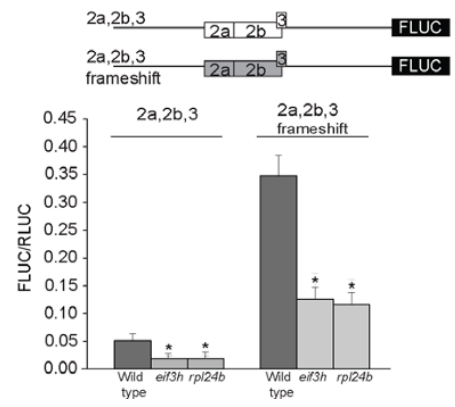

Figure 1 Both elF3h and RPL24B are required for efficient translation of the uORF-containing AtbZip11 mRNA. Data are

from transient dual-luciferase gene expression assays in ten day old seedlings. The respective $5^{\prime}$ leader is fused to firefly luciferase and is expressed in the presence of a reference gene expressing Renilla luciferase as an internal control for transformation efficiency. Both genes are transcribed from a CaMV 355 promoter [13]. (A) Schematic of the $5^{\prime}$ leader of the AtbZip 11 mRNA. Boxes numbered 1 to 4 represent uORFs. In the $\triangle$ AtbZip 11 mutant the five UAUGs are replaced with stop codons [13]. Bars denote standard error; $\mathrm{n}=$ 7 to $10 ;{ }^{*} P<0.002$ by Student's t-test when compared to wild type. The gel images below the graph show mRNA levels for FLUC and RLUC as determined by subsaturating RT-PCR. Gel lanes correspond to the bars in the graph above. (B) Recognition of the uAUG start codons in AtbZip11. Like eif3h [13], rpl24b is not defective in recognizing the weak start codons, UAUG1 and UAUG2a, nor a strong version of UAUG4. (C) Testing the dependence of translation on the UORF peptide sequence. Both rp/24b and eif3h are inhibited to a similar degree by UORFs encoding the original UORF2 and UORF3 peptide sequences (white box in the schematic) and alternative peptide sequences generated by site-directed mutagenesis and a pair of compensatory frame shift mutations (gray box). For details on plasmid construction see [13].
The constructs shown in Fig. 2B demonstrated the negative effect on translation when a uORF overlaps the main ORF, a situation found in the mRNA for the mammalian bZip protein, ATF4 [33]. The reduction of translation by the overlapping $\mathrm{uORF}$ in the wild type points to the fact that wild-type ribosomes reinitiate after translating the upstream uORF. In contrast, in eif $3 h$, and evidently also in rpl24b, translation was poor even in the absence of the ribosome-trapping overlapping $\mathrm{uORF}$, suggesting that reinitiation after the first uORF is poor. The yeast GCN4 5' leader is another example of a $5^{\prime}$ leader that requires reinitiation for full expression [34], although the GCN4 uORFs are short and translational attenuation in eif $3 h$ is less pronounced [13]. Again, rpl24b behaved similarly to eif3h (Fig. 2C). Taken together, all these data suggest that RPL24B and eIF3h have closely related molecular functions during translation reinitiation.

\section{Many eif3h mutant phenotypes are reminiscent of defects} in auxin transport or response

The emerging hypothesis that RPL24B cooperates with eIF3h predicts that mutations in the two genes have overlapping developmental phenotypes. Instead of a functional inflorescence with leaves and flowers, eif $3 h$ mutant plants sometimes formed a pin-formed shoot, especially when shifted from short-day to long-day growth conditions $(20 \%, \mathrm{n}=90)$ (Fig. 3A). Pin-formed shoots are characteristic of defects in auxin transport or response, for example the pin1 mutant (Fig. 3B[27]) and mutations in the auxin response transcription factor, MONOPTEROS (MP)/ARF5 [35]. These data suggest that eIF3h may boost translation of proteins needed for auxin transport or auxin response. In further support of auxin response defects, some eif3h mutant seedlings had only a single cotyledon or two cotyledons of unequal size, similar to the $m p$ (arf5) mutant (Fig. 3D) and $r p l 24 b / s t v 1$ [21]. Auxin defects often reveal themselves by cul-de-sac vascular elements in the cotyledons, and such defects were readily observed in the eif3h mutant (Fig. 3E).

The siliques of the eif $3 h$ mutant were shorter than wild type, and typically the valves initiated at an unusual distance from the node. Occasionally a valve was missing from one side of the silique, which is reminiscent of the ettin/arf3 mutant (Fig. 3C; [30,31]). In keeping with the hypothesis that eIF3h cooperates with RPL24B, $r p l 24 b / s t v 1$ displayed similar valve defects ([21] Fig. 3C). Notably, the rpl24b mutants will also display pin-formed shoots when enhanced by an ettin/arf3 mutation [21].

To address the postulated auxin response defects in the eif $3 h$ mutant at a cellular level in situ, the auxin responsive DR5:GFP gene and a PIN1-GFP gene under the control of the PIN1 promoter (PIN1:PIN1-GFP) 


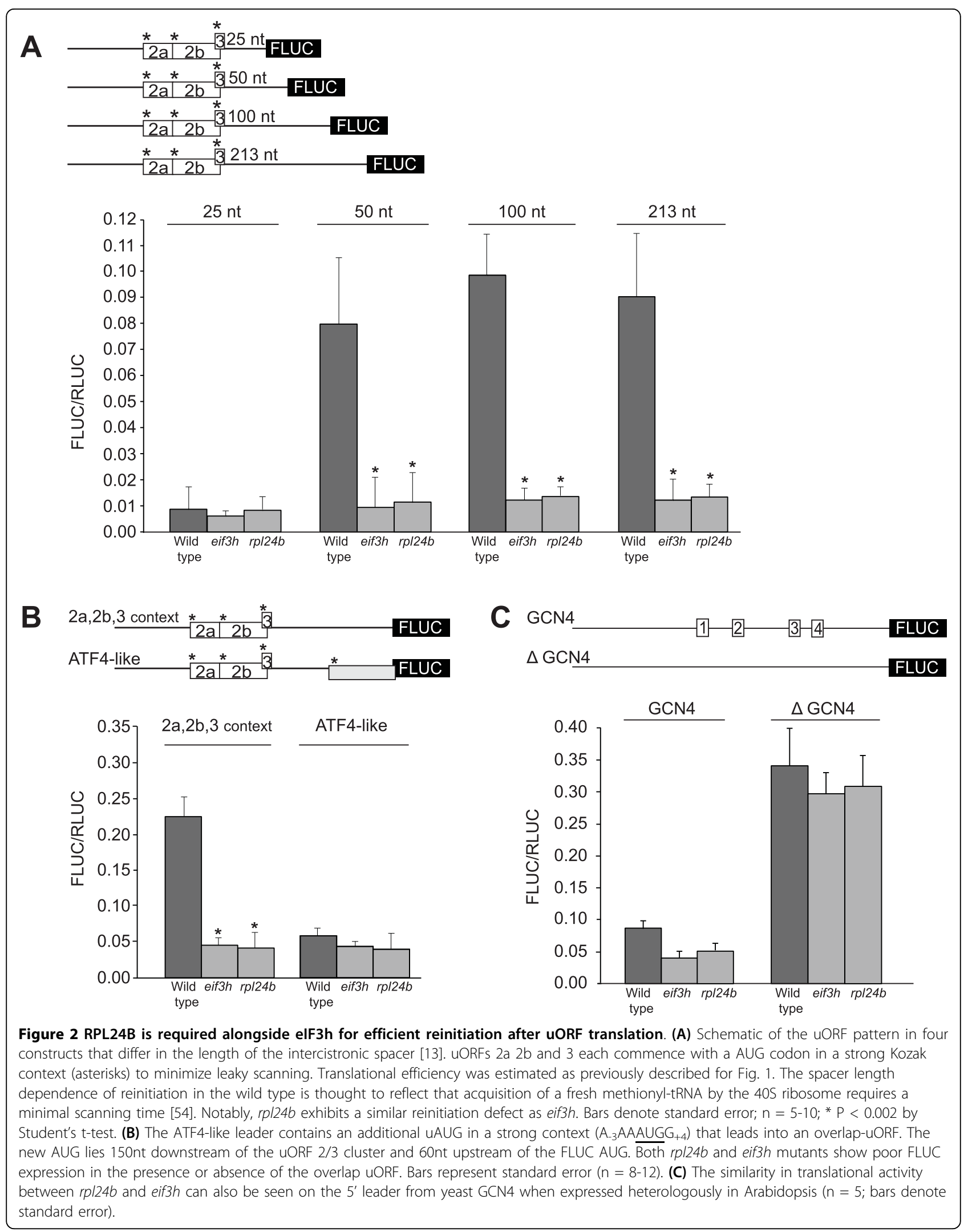




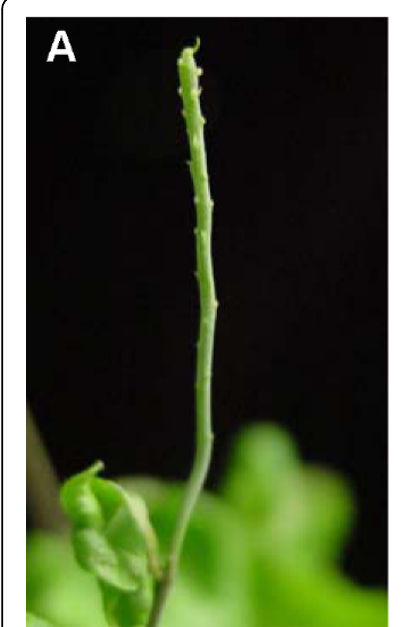

eif3h

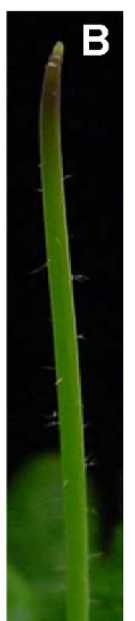

pin1

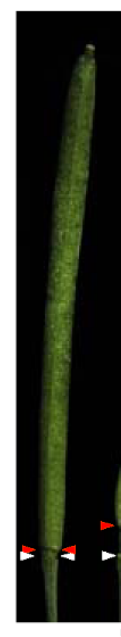

W

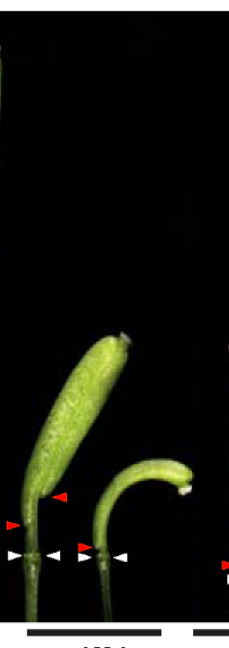

eif3h

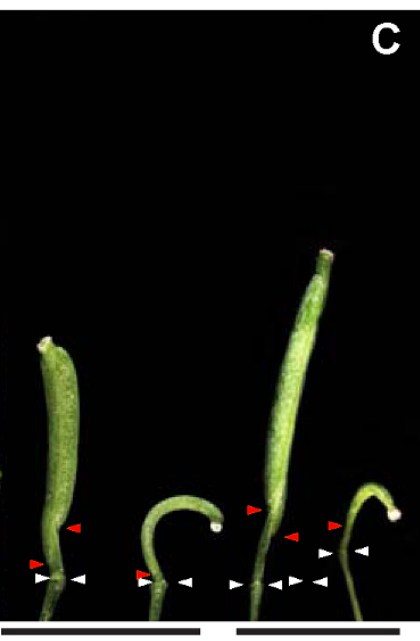

rp/24b

ett-2

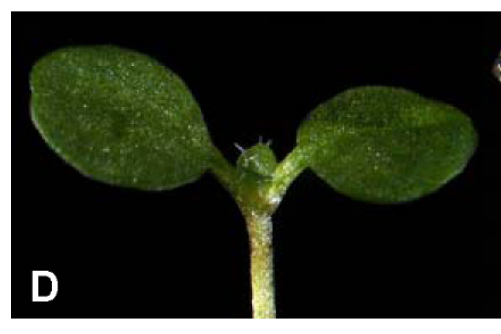

WT

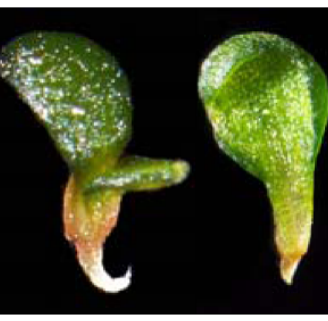

$m p$

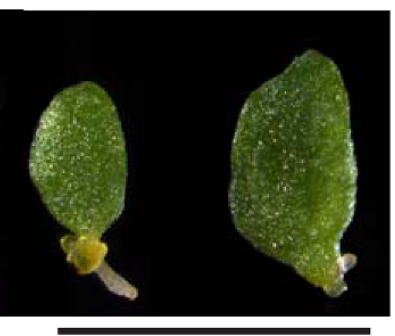

eif3h

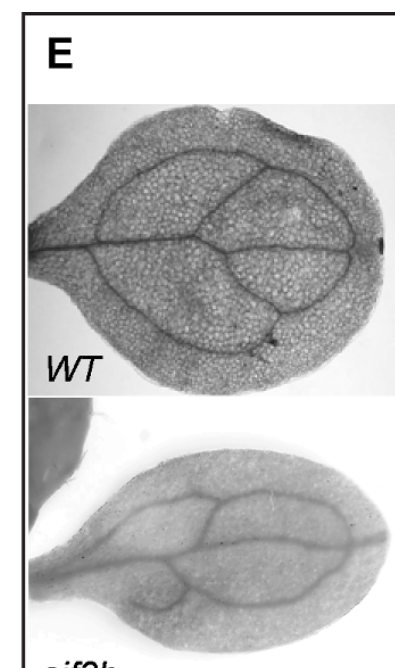

eif3h

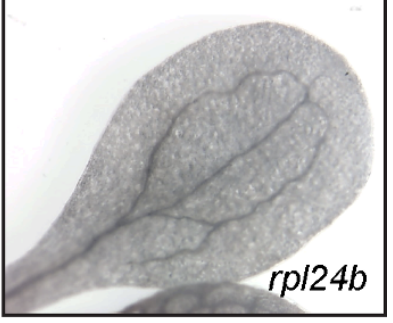

Figure 3 eif3h phenotypes reminiscent of defects in auxin transport or response. (A) eif3h naked shoot. Compared to the canonical pins of the pin1 mutant (B), eif3h pins tended to bear scaly, rudimentary organs. (C) eif3h siliques show defects in carpel development, similar to those of rpl24b/stv1-1 or ett-2, an allele of ARF3. White arrowheads point to the last node carrying stamens and red arrowheads point to the basal end of the carpel valves. (D) Rare monocotyledon phenotype of eif3h seedlings, similar to that of mp, an allele of ARF5. (E) Cotyledons were cleared to reveal defects in vascular development. Similar defects as in eif3h can be seen in rp/24b/stv1-1 [21].

were crossed into the eif3h mutant. While DR5:GFP was highly expressed in the wild-type root tip, it was significantly reduced in the eif3h mutant (Fig. 4A, B). Likewise, the PIN1:PIN1-GFP expression was significantly reduced in the eif3h mutant roots (Fig. 4C, D). The potential for low expression of the PIN1 auxin efflux carrier in the eif3h mutant presents a possible explanation for the appearance of pin-formed inflorescence shoots.

\section{elF3h boosts translation of uORF-containing ARF mRNAs}

eIF3h counteracts the translational repression by uORFs $[8,12,13]$. Among auxin-related genes, most $A R F \mathrm{~s}$ harbor multiple uORFs. ARF5, ARF6, and ARF11 each have seven or more upstream AUGs (uAUGs) (Fig. 5). In contrast, uORFs were uncommon among $A U X / I A A$ and YUCCA mRNAs, TIR1 auxin receptor homologs, and PIN mRNAs (Table 1). The abundance of uORFs in the $A R F 5^{\prime}$ leaders indicates that these mRNAs are potential clients of eIF3h.
A protoplast transformation assay based on in vitro transcribed mRNA was adopted to observe the translation efficiency of specific mRNA 5 ' leaders in the eif $3 h$ mutant. While translation with a PIN1 leader, which lacks uORFs, or TIR1 and AUX1 leaders with only one short uORF, was not dramatically affected, the ARF leaders with multiple uORFs were poorly translated in the eif3h mutant (Fig. 6B, C). Translation of ARF3 and ARF5 were previously shown to be dependent on RPL24B. Results shown here now indicate that both eIF3h and RPL24B are required for maximal translation of the same target mRNA.

\section{Discussion}

\section{Coordination between 605 subunit and elF3 during} reinitiation

Reinitiation can be defined as translation initiation downstream of a uORF by a ribosome that has just terminated translation at the uORF termination codon. It is the small (40S) subunit that reinitiates, while the $60 \mathrm{~S}$ 

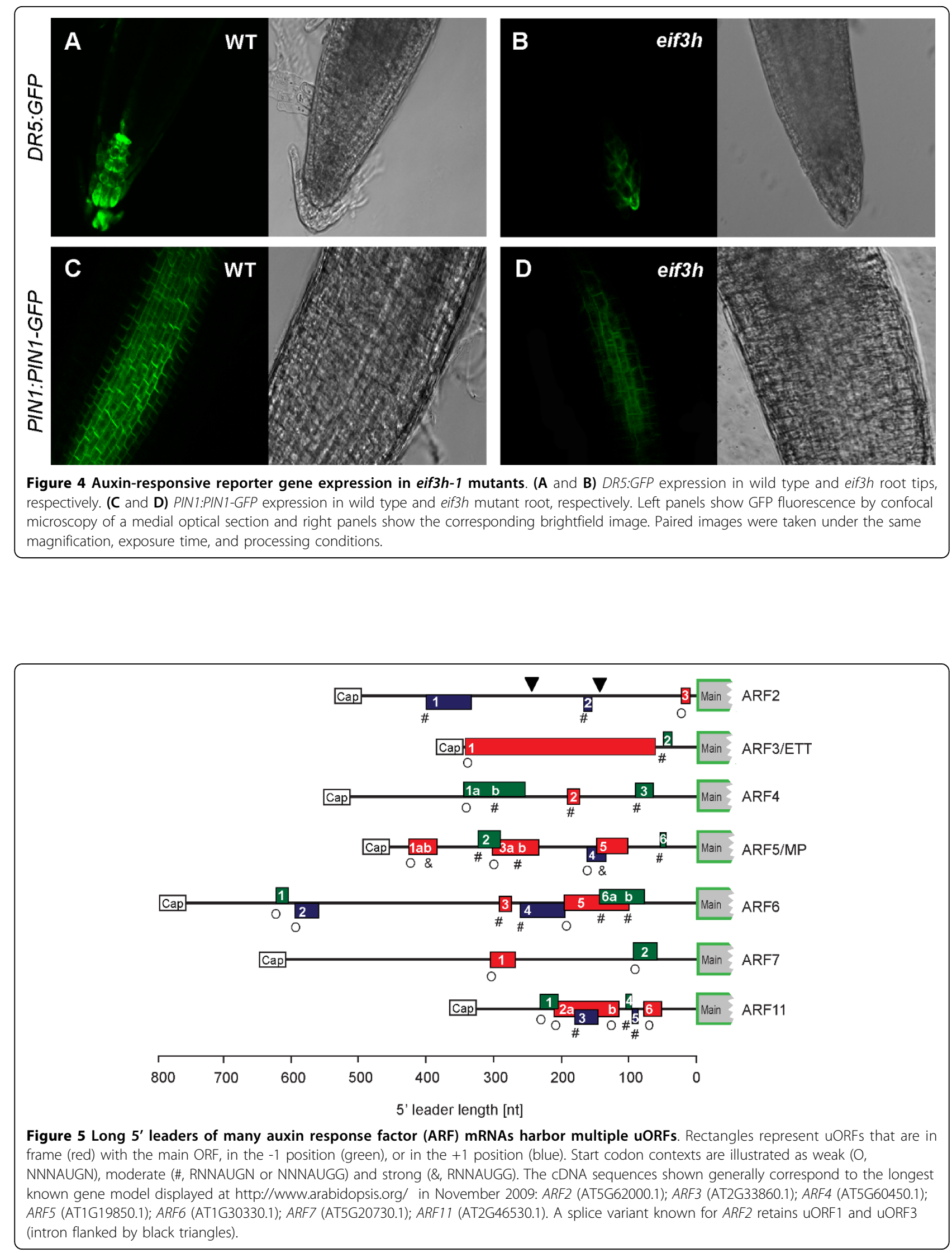
Table 1 uAUG abundance in 5' leader sequences of auxin related mRNAs

\begin{tabular}{cccccc}
\hline $\begin{array}{c}\text { Gene } \\
\text { family }\end{array}$ & $\begin{array}{c}\text { Leader sequences } \\
\text { available }\end{array}$ & $\begin{array}{c}\text { No. of uAUG/ } \\
\text { leader }\end{array}$ & $\begin{array}{c}\text { No. of uAUG/ } \\
\text { 100nt }\end{array}$ & $\begin{array}{c}\text { \% Leaders with 2 or more } \\
\text { uAUG }\end{array}$ & $\begin{array}{c}\text { \% Leaders with } \mathbf{3} \text { or more } \\
\text { uAUG }\end{array}$ \\
\hline ARF & 14 & 3.3 & 0.9 & 64 & 36 \\
YUCCA & 3 & 1.0 & 0.3 & 33 & 0 \\
$\begin{array}{c}\text { AFB/TIR1- } \\
\text { like }\end{array}$ & 5 & 0.8 & 0.3 & 20 & 0 \\
AUX/IAA & 26 & 0.4 & 0.3 & 12 & 0 \\
PIN & 6 & 0.16 & 0.16 & 0 & 0 \\
\hline
\end{tabular}

Note: Data based on the longest mRNA 5' leader sequence available in the Genome Browser at the Arabidopsis Information Resource http://www.arabidopsis.org/ on June $27,2009$.

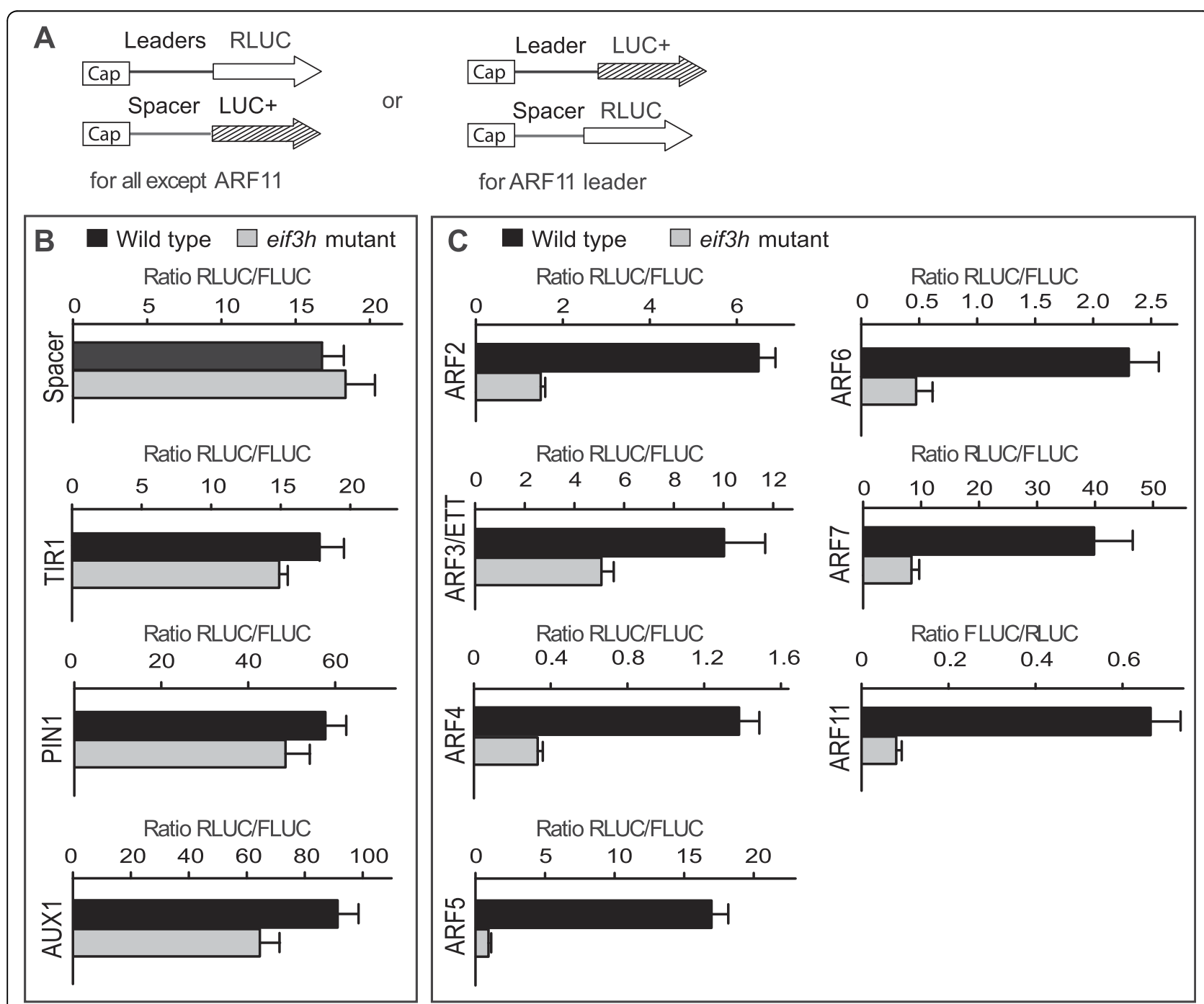

Figure 6 The $\mathbf{5}^{\prime}$ leaders of many uORF-containing ARF mRNAs render translation dependent on elF3h. (A) Schematic view of the mRNAs for protoplast transformation. Open arrows represent RLUC ORF, hatched arrows represent codon-optimized FLUC (LUC+). mRNAs were prepared by in vitro transcription with SP6 RNA polymerase. An equal amount of internal control (Spacer-LUC+) mRNA was added to the 5' leader-RLUC mRNA to be tested as an internal control for transformation efficiency. (B and C) Translational efficiency on the given ARF $5^{\prime}$ leader is expressed as the mean RLUC/FLUC ratio with standard errors from three replicate transformations. Data from several other auxin related $5^{\prime}$ leaders are shown for comparison. PIN1 does not contain UORFs. AUX1 and TIR1 each have one short UORF of six codons. 
subunit is most likely recycled. The efficiency of reinitiation varies depending on the sequence context in and around the uORF. Reinitiation can be quite efficient when the uORF is short. Reinitiation becomes less efficient as the length of the uORF increases or as the time necessary to translate it increases. Translation of a regular protein-coding ORF will typically abolish the reinitiation competence $[3,36]$. The mechanism of reinitiation is not well understood. Compared to regular, cap-dependent, initiation, one predicts the following unique aspects as the small subunit of the ribosome resumes scanning. First, the 40S subunit of the ribosome resumes scanning without apparent contact to the cap binding protein eIF4E. Second, the $40 \mathrm{~S}$ is not charged with a tRNA or ternary complex and must reaquire it. And third, the 40S lacks several other initiation factors, such as eIF1, eIF1A, both of which should have been ejected from the $40 \mathrm{~S}$ during $40 \mathrm{~S}-60 \mathrm{~S}$ subunit joining. eIF1 and $1 \mathrm{~A}$ may, however, rejoin the $40 \mathrm{~S}$ subunit after termination to participate in 40S-60S subunit separation [19].

Many case studies of translation reinitiation have implicated eIF3 in the process. eIF3h [8] and eIF3a [18] help when uORFs are short or generic. Other studies $[12,13,37]$ attribute a role to eIF3 for reinitiation after longer uORFs. Reinitiation after long ORFs is rare and requires either specialized RNA sequence elements [38] or specialized reinitiation factors [39-41]. Yet, we suspect that eIF3 is required in these cases as well. Specifically, the reinitiation motif of feline calicivirus RNA binds to eIF3 [38]. And the reinitiation factor, TAV, of cauliflower mosaic virus interacts with the $g$ subunit of eIF3 [39], aside from a newly discovered plant protein termed re-initiation supporting protein (RISP) [41]. These and other data have given rise to the hypothesis that eIF3 remains attached to the $40 \mathrm{~S}$ for a few codoncycles of translation elongation [e.g. [3,13,18,37]], although direct biochemical evidence for this notion is still lacking.

Meanwhile, circumstantial evidence indicates that reinitiation also requires proteins of the large ribosomal subunit [42]. The uORFs in the ARF3 and ARF5 mRNAs are less inhibitory when RPL24B is intact [21]. Second, the CaMV reinitiation factor, TAV, interacts not only with eIF3g but also with RPL24 [39], although it has not yet been shown that mutations of eIF3g or RPL24 will impede the reinitiation activity of TAV.

The experiments presented here further test the hypothesis that a subunit of the 60S ribosome, RPL24B, and a subunit of eIF3 cooperate to foster reinitiation. We newly demonstrate that mutations in both $r p l 24 b$ and eif $3 h$ inhibit reinitiation of the same uORF-containing mRNA, AtbZip11. Moreover, the ARF3 and ARF5 mRNAs, which are poorly translated in $r p l 24 b$, are also poorly translated in eif $3 h$, alongside with other
uORF-studded ARF mRNAs. These findings would predict that $r p l 24 b$ and eif $3 h$ share visible developmental phenotypes, which is indeed the case. Both display defects in the development of the cotyledon vasculature and the valves of the fruit, a phenotype characteristic of arf3/ettin mutants. The pin-formed inflorescences that can form in eif $3 h$ mutants, which are characteristic of certain arf5 alleles [35], were not seen in rpl24b per se, but were seen when $r p l 24 b$ was enhanced by an arf3 mutation [21]. Although the phenotype of $r p l 24 b$ is generally less dramatic than that of eif $3 h$, all together, these findings provide new evidence for a close functional interaction between eIF3 and the 60S subunit.

The mode of interaction between eIF3h and RPL24 could be physically direct or indirect, or they may act independently. Concerning a direct interaction, we consider that RPL24B is located at the leading edge (the side of mRNA entry) of the $60 \mathrm{~S}$ subunit, and more specifically at the $40 \mathrm{~S} / 60 \mathrm{~S}$ interface where it forms the intersubunit bridge B7 toward the long helix 44 in the $40 \mathrm{~S}$ subunit [43]. Meanwhile, eIF3 binds to the lagging edge of the 40S subunit just below the mRNA exit channel [44]. Thus, assuming that eIF3 might remain bound to an $80 \mathrm{~S}$ ribosome, eIF3h and RPL24 would reside on opposite faces of the ribosome and would be far apart. Thus, a direct interaction seems unlikely because it would require that eIF3 detach from the $40 \mathrm{~S}$, or, possibly, that the interaction take the form of a bridge between separate $60 \mathrm{~S}$ and $40 \mathrm{~S}$ subunits that are not part of the same $80 \mathrm{~S}$ ribosome. An indirect interaction between RPL24 and eIF3h would occur if eIF3 was attached to an $80 \mathrm{~S}$ ribosome. Under this circumstance, it may seem surprising that mutations in two remote components of this molecular machine would affect reinitiation in similar ways. However, it is worth to point to related precedents. For example, mutations in several, physically separate, RPL proteins affect plant development in remarkably similar ways [45]. Finally, eIF3h and RPL24 might bolster reinitiation independently. For example, eIF3h might bolster the competence to resume scanning after uORF termination [13], and RPL24 might affect elongation. Slowing elongation on a uORF can reduce the efficiency of reinitiation [36].

\section{Translational control of development}

The developmental defects identified in the eif $3 h$ mutants underscore that translational control by uORFs might play an important role in modulating auxin responses during plant development. Defects in the carpel valves in $r p l 24 b / s t v 1$ were interpreted as a consequence of the undertranslation of ARFs [21], and this phenotype likewise appeared in eif3h mutants. Mutants with defects in auxin action typically have defects in vascular development, as seen here in eif $3 h$. Because $A R F \mathrm{~s}$ 
activate transcription from the $D R 5$ promoter [46], one expects underexpression of DR5:GFP, which was in fact observed in the eif3h mutant (Fig. 4A, B), indicating a reduced auxin response. Moreover, because ARF5/MP stimulates PIN1 expression and thus auxin efflux $[46,47]$, the undertranslation of $A R F 5$ in the eif3h mutant (Fig. 6) would cause underexpression of PIN1: PIN1-GFP, as well as a tendency for pin-formed shoots, as was indeed observed (Fig. 4C, D; Fig. 3A). Upregulation of several $A U X / I A A$ mRNAs in the eif $3 h$ mutant [12] may also contribute to reduce the PIN1:PIN1-GFP expression [48]. Taken together, the auxin related growth defects of the eif $3 h$ mutant may be caused in part by reduced translation of $A R F \mathrm{~s}$. Mutations affecting ribosomal proteins other than RPL24 also compromise development $[45,49]$; identifying whether the underlying mechanisms operate in conjunction with eIF3 will be a topic for future investigation.

\section{Conclusions}

This study indicated that both eIF3h and RPL24 promote the translation of uORF-containing mRNAs. The $r p l 24 b$ and eif $3 h-1$ mutants displayed similar translational defects on the AtbZip11 mRNA and its variants, as well as on mRNAs for auxin response transcription factors. The two mutants also showed similar auxin-related developmental defects. The translation initiation factor eIF3h may play an important role in translational control by communicating with RPL proteins and thus enhancing the reinitiation competence of the large subunit of the ribosome.

\section{Methods}

\section{Plant growth conditions}

Growth conditions for wild type (Wassiliweskija ecotype) and the eif3h-1 allele (At1g10840), which harbors a T-DNA insertion in the 10th of 12 exons, have been described [12]. The rpl24b mutant allele (At3g53020) is allele stv1-1 (Arabidopsis Biological Resource Center stock number CS6957) in the Wassiliweskija ecotype. DR5:GFP and PIN1:PIN1-GFP transgenes were introduced into the eif3h-1 background and Wassiliweskija wild-type by crossing.

\section{Molecular cloning}

The plasmids for in vitro transcription were made in the TA-cloning vector pKRX [50] and contained the SP6 phage promoter, the translational leader from tobacco etch virus (TL) and the coding region of firefly luciferase (FLUC) or LUC+ (from pGL3-basic, Promega, Madison, WI) or Renilla luciferase (RLUC; [51]) followed by a 70 nucleotide long poly-A tail. The TL 5 ' leader was replaced with the respective leader sequence to be assayed. The $5^{\prime}$ leader called Spacer is the multiple cloning site of pGL3-basic.

\section{Microscopy}

GFP fluorescence was visualized on a Leica SPI 2 laser scanning confocal microscope.

\section{DNA based expression assay after transient transformation}

Wild-type, $r p l 24 b / s t v 1-1$ and eif3h-1 mutant plants were grown for ten days on MS agar plates with $1 \%$ sucrose. Plasmids carrying dual-luciferase constructs were introduced by particle bombardment as previously described [12]. Transformed seedlings were incubated at $22^{\circ} \mathrm{C}$ in a lighted growth chamber for 8 hours before assaying for luciferase activity. Activities of the experimental luciferase and the reference luciferase were measured in a single protein extract using the Dual Luciferase system (Promega, Madison, WI) in the TD-20/20 luminometer (Turnerdesigns, Sunnyvale, CA). Mean ratios of experimental and reference luciferase from at least 3 biological replicates were used to compare the translation efficiency between wild type and eif3h mutant.

\section{Protoplast preparation and mRNA transformation}

Protoplasts were prepared from shoots of wild-type or mutant 7-day-old Arabidopsis seedlings [52] and were transformed with 200ng mRNA using the polyethyleneglycol method [53] as described [13]. The protoplasts were incubated in a 24 well plate for 3 hours in the dark at room temperature, then harvested by centrifugation for luciferase assays.

\footnotetext{
Acknowledgements

We are grateful for transgenic lines contributed by Klaus Palme and Thomas Guilfoyle, and for numerous cDNAs clones as well as the rp/24b/stv1-1 mutant distributed by the Arabidopsis stock center. We appreciate access to microscopes granted by Mariano Labrador, Andreas Nebenführ and John Dunlap of the Biology Microscopy Core Facility and discussions with John Golz, Andreas Nebenführ, and Elena Shpak. This work was supported by a grant from the DOE Energy Biosciences Program (DE-FG02-96ER20223) and by BARD grant IS3901-06C.
}

\section{Author details}

'Genome Science and Technology Program, The University of Tennessee, Knoxville, TN 37996, USA. ${ }^{2}$ Department of Biochemistry, Cellular and Molecular Biology, The University of Tennessee, Knoxville, TN 37996, USA. ${ }^{3}$ Laboratory of Gene Regulation and Development, Eunice Kennedy Shriver National Institute of Child Health and Human Development, Bethesda, MD 20892, USA

\section{Authors' contributions}

FZ performed developmental and gene expression studies for Figs. 3, 4, 5 and 6 and Table 1, BR carried out gene expression assays in Fig. 1-2. AGV directed the research and wrote the manuscript. All authors read and approved the final manuscript.

Received: 8 May 2010 Accepted: 27 August 2010 Published: 27 August 2010

\section{References}

1. Sachs MS, Geballe AP: Downstream control of upstream open reading frames. Genes Dev 2006, 20:915-921. 
2. Sonenberg $N$, Hinnebusch AG: New modes of translational control in development, behavior, and disease. Mol Cell 2007, 28:721-729.

3. Jackson RJ, Hellen CU, Pestova TV: The mechanism of eukaryotic translation initiation and principles of its regulation. Nat Rev Mol Cell Biol 2010, 11:113-127.

4. Kawaguchi R, Bailey-Serres J: Regulation of translational initiation in plants. Curr Opin Plant Biol 2002, 5:460-465.

5. Hanfrey C, Elliott KA, Franceschetti M, Mayer MJ, Illingworth C, Michael AJ: A dual upstream open reading frame-based autoregulatory circuit controlling polyamine-responsive translation. J Biol Chem 2005, 280:39229-39237.

6. Imai A, Hanzawa Y, Komura M, Yamamoto KT, Komeda Y, Takahashi T: The dwarf phenotype of the Arabidopsis acl5 mutant is suppressed by a mutation in an upstream ORF of a bHLH gene. Development 2006, 133:3575-3585.

7. Hanson J, Hanssen M, Wiese A, Hendriks MM, Smeekens S: The sucrose regulated transcription factor bZIP11 affects amino acid metabolism by regulating the expression of ASPARAGINE SYNTHETASE1 and PROLINE DEHYDROGENASE2. Plant J 2008, 53:935-949.

8. Kim BH, Cai $X$, Vaughn JN, von Arnim AG: On the functions of the $h$ subunit of eukaryotic initiation factor 3 in late stages of translation initiation. Genome Biol 2007, 8:R60.

9. Rajkowitsch L, Vilela C, Berthelot K, Ramirez CV, McCarthy JE: Reinitiation and recycling are distinct processes occurring downstream of translation termination in yeast. J Mol Biol 2004, 335:71-85.

10. Rahmani F, Hummel M, Schuurmans J, Wiese-Klinkenberg A, Smeekens S, Hanson J: Sucrose control of translation mediated by an upstream open reading frame-encoded peptide. Plant Physiol 2009, 150:1356-1367.

11. Wiese A, Elzinga N, Wobbes B, Smeekens S: A conserved upstream open reading frame mediates sucrose-induced repression of translation. Plant Cell 2004, 16:1717-1729.

12. Kim $\mathrm{TH}$, Kim BH, Yahalom A, Chamovitz DA, von Arnim AG: Translational regulation via $5^{\prime}$ mRNA leader sequences revealed by mutational analysis of the Arabidopsis translation initiation factor subunit elF3h. Plant Cell 2004, 16:3341-3356.

13. Roy B, Vaughn JN, Kim BH, Zhou F, Gilchrist MA, von Arnim AG: The $h$ subunit of elF3 promotes reinitiation competence during translation of mRNAs harboring upstream open reading frames. RNA 2010, 16:748-761.

14. Burks EA, Bezerra PP, Le H, Gallie DR, Browning KS: Plant initiation factor 3 subunit composition resembles mammalian initiation factor 3 and has a novel subunit. J Biol Chem 2001, 276:2122-2131.

15. Hinnebusch AG: elF3: a versatile scaffold for translation initiation complexes. Trends Biochem Sci 2006, 31:553-562.

16. Nielsen KH, Szamecz B, Valasek L, Jivotovskaya A, Shin BS, Hinnebusch AG: Functions of elF3 downstream of $48 \mathrm{~S}$ assembly impact AUG recognition and GCN4 translational control. Embo J 2004, 23:1166-1177.

17. Valasek $L$, Nielsen $\mathrm{KH}$, Zhang F, Fekete CA, Hinnebusch AG: Interactions of eukaryotic translation initiation factor 3 (elF3) subunit NIP1/c with elF1 and elF5 promote preinitiation complex assembly and regulate start codon selection. Mol Cell Biol 2004, 24:9437-9455.

18. Szamecz B, Rutkai E, Cuchalova L, Munzarova V, Herrmannova A, Nielsen KH, Burela L, Hinnebusch AG, Valasek L: elF3a cooperates with sequences $5^{\prime}$ of uORF1 to promote resumption of scanning by post-termination ribosomes for reinitiation on GCN4 mRNA. Genes Dev 2008, 22:2414-2425.

19. Pisarev AV, Hellen CU, Pestova TV: Recycling of eukaryotic posttermination ribosomal complexes. Cell 2007, 131:286-299.

20. Masutani M, Sonenberg N, Yokoyama S, Imataka H: Reconstitution reveals the functional core of mammalian elF3. Embo J 2007, 26:3373-3383.

21. Nishimura T, Wada T, Yamamoto KT, Okada K: The Arabidopsis STV1 protein, responsible for translation reinitiation, is required for auxinmediated gynoecium patterning. Plant Cell 2005, 17:2940-2953.

22. Aida M, Vernoux T, Furutani M, Traas J, Tasaka M: Roles of PIN-FORMED1 and MONOPTEROS in pattern formation of the apical region of the Arabidopsis embryo. Development 2002, 129:3965-3974.23.

23. Friml J, Vieten A, Sauer M, Weijers D, Schwarz H, Hamann T, Offringa R, Jürgens G: Efflux-dependent auxin gradients establish the apical-basal axis of Arabidopsis. Nature 2003, 426:147-153.

24. Shani $\mathrm{E}$, Yanai $\mathrm{O}$, Ori $\mathrm{N}$ : The role of hormones in shoot apical meristem function. Curr Opin Plant Biol 2006, 9:484-489.
25. Reinhardt D, Pesce ER, Stieger P, Mandel T, Baltensperger K, Bennett M, Traas J, Friml J, Kuhlemeier C: Regulation of phyllotaxis by polar auxin transport. Nature 2003, 426:255-260.

26. Heisler MG, Ohno C, Das P, Sieber P, Reddy GV, Long JA, Meyerowitz EM: Patterns of auxin tfransport and gene expression during primordium development revealed by live imaging of the Arabidopsis inflorescence meristem. Curr Biol 2005, 15:1899-1911.

27. Teale WD, Paponov IA, Palme K: Auxin in action: signalling, transport and the control of plant growth and development. Nat Rev Mol Cell Biol 2006, 7:847-859

28. Hardtke CS, Berleth T: The Arabidopsis gene MONOPTEROS encodes a transcription factor mediating embryo axis formation and vascular development. Embo J 1998, 17:1405-1411.

29. Schütz M, Berleth T, Mattsson J: Multiple MONOPTEROS-dependent pathways are involved in leaf initiation. Plant Physiol 2008, 148:870-880.

30. Sessions RA, Zambryski PC: Arabidopsis gynoecium structure in the wild and in ettin mutants. Development 1995, 121:1519-1532.

31. Nemhauser JL, Feldman LJ, Zambryski PC: Auxin and ETTIN in Arabidopsis gynoecium morphogenesis. Development 2000, 127:3877-3888.

32. Garcia D, Collier SA, Byrne ME, Martienssen RA: Specification of leaf polarity in Arabidopsis via the trans-acting siRNA pathway. Curr Biol 2006, 16:933-938.

33. Harding HP, Novoa I, Zhang Y, Zeng H, Wek R, Schapira M, Ron D: Regulated translation initiation controls stress-induced gene expression in mammalian cells. Mol Cell 2000, 6:1099-1108.

34. Hinnebusch AG: Translational regulation of GCN4 and the general amino acid control of yeast. Annu Rev Microbiol 2005, 59:407-450.

35. Przemeck GK, Mattsson J, Hardtke CS, Sung ZR, Berleth T: Studies on the role of the Arabidopsis gene MONOPTEROS in vascular development and plant cell axialization. Planta 1996, 200:229-237.

36. Kozak M: Constraints on reinitiation of translation in mammals. Nucleic Acids Res 2001, 29:5226-5232.

37. Pöyry TA, Kaminski A, Jackson RJ: What determines whether mammalian ribosomes resume scanning after translation of a short upstream open reading frame? Genes Dev 2004, 18:62-75.

38. Pöyry TA, Kaminski A, Connell EJ, Fraser CS, Jackson RJ: The mechanism of an exceptional case of reinitiation after translation of a long ORF reveals why such events do not generally occur in mammalian mRNA translation. Genes Dev 2007, 21:3149-3162.

39. Park HS, Himmelbach A, Browning KS, Hohn T, Ryabova LA: A plant viral "reinitiation" factor interacts with the host translational machinery. Cell 2001, 106:723-733

40. Park HS, Browning KS, Hohn T, Ryabova LA: Eucaryotic initiation factor 4B controls elF3-mediated ribosomal entry of viral reinitiation factor. Embo $J$ 2004, 23:1381-1391.

41. Thiébeauld O, Schepetilnikov M, Park HS, Geldreich A, Kobayashi K, Keller M, Hohn T, Ryabova LA: A new plant protein interacts with elF3 and 60S to enhance virus-activated translation re-initiation. Embo J 2009, 28:3171-3184.

42. Imai A, Komura M, Kawano E, Kuwashiro $Y$, Takahashi T: A semi-dominant mutation in the ribosomal protein L10 gene suppresses the dwarf phenotype of the acl5 mutant in Arabidopsis thaliana. Plant J 2008, 56:881-890.

43. Spahn CM, Beckmann R, Eswar N, Penczek PA, Sali A, Blobel G, Frank J: Structure of the $80 \mathrm{~S}$ ribosome from Saccharomyces cerevisiae-tRNAribosome and subunit-subunit interactions. Cell 2001, 107:373-386.

44. Siridechadilok B, Fraser CS, Hall RJ, Doudna JA, Nogales E: Structural roles for human translation factor elF3 in initiation of protein synthesis. Science 2005, 310:1513-1515.

45. Byrne ME: A role for the ribosome in development. Trends Plant Sci 2009, 14:512-519.

46. Wenzel CL, Schuetz M, Yu Q, Mattsson J: Dynamics of MONOPTEROS and PIN-FORMED1 expression during leaf vein pattern formation in Arabidopsis thaliana. Plant J 2007, 49:387-398.

47. Schütz M, Berleth T, Mattsson J: Multiple MONOPTEROS-dependent pathways are involved in leaf initiation. Plant Physiol 2008, 148:870-880.

48. Vieten A, Vanneste S, Wisniewska J, Benkova E, Benjamins R, Beeckman T, Luschnig C, Friml J: Functional redundancy of PIN proteins is accompanied by auxin-dependent cross-regulation of PIN expression. Development 2005, 132:4521-4531. 
49. Degenhardt RF, Bonham-Smith PC: Arabidopsis ribosomal proteins RPL23aA and RPL23aB are differentially targeted to the nucleolus and are desperately required for normal development. Plant Physiol 2008, 147:128-142.

50. Schütte BC, Ranade K, Pruessner J, Dracopoli N: Optimized conditions for cloning PCR products into an Xcml T-vector. Biotechniques 1997, 22:40-42, 44.

51. Subramanian C, Woo J, Cai X, Xu X, Servick S, Johnson CH, Nebenfuhr $A$, von Arnim AG: A suite of tools and application notes for in vivo protein interaction assays using bioluminescence resonance energy transfer (BRET). Plant J 2006, 48:138-152.

52. Yoo SD, Cho YH, Sheen J: Arabidopsis mesophyll protoplasts: a versatile cell system for transient gene expression analysis. Nat Protoc 2007, 2:1565-1572.

53. Gallie DR: Introduction of mRNA to plant protoplasts using polyethylene glycol. Plant Cell Reports 1993, 13:119-122.

54. Kozak M: Effects of intercistronic length on the efficiency of reinitiation by eucaryotic ribosomes. Mol Cell Biol 1987, 7:3438-3445.

doi:10.1186/1471-2229-10-193

Cite this article as: Zhou et al.: Translation reinitiation and development are compromised in similar ways by mutations in translation initiation factor elF3h and the ribosomal protein RPL24. BMC Plant Biology 2010 10:193.

\section{Submit your next manuscript to BioMed Central} and take full advantage of:

- Convenient online submission

- Thorough peer review

- No space constraints or color figure charges

- Immediate publication on acceptance

- Inclusion in PubMed, CAS, Scopus and Google Scholar

- Research which is freely available for redistribution

Submit your manuscript at www.biomedcentral.com/submit 